\title{
Do you know the radiation dose your patients receive from your CT scanner?
}

\section{Chris Welman MB ChB \\ Savvas Andronikou MB BCh, FCRad (D), FRCR (Lond) \\ Ebrahim Kader MB ChB \\ Department of Paediatric Radiology, University of Cape Town and Institute of Child Health Red Cross War Memorial Children's Hospital, Cape Town}

\section{Abstract}

The number of computed tomography $(\mathrm{CT})$ examinations and new indications for $\mathrm{CT}$ are increasing in frequency worldwide. While CT makes up only $4 \%$ of medical examinations, it might contribute as much as $40 \%$ of the total collective radiation dose to the population. Radiologists and referring clinicians should make sure that the CT examination is indicated. Doses can often approach or exceed levels known to increase the probability of cancer. This is especially relevant in children where dose reductions of up to $80 \%$ can be obtained by adjusting the exposure factors. The most important factors are decreased milliampere seconds ( $\mathrm{mAs}$ ) and increased pitch.

\section{Introduction}

Part of the work of a radiologist is to advise on the appropriate investigation for specific clinical problems. As radiation workers we are entrusted with the task of assessing whether the benefit from an investigation outweighs the radiation risk involved. Practically, however, most radiologists in clinical practice are not sufficiently aware of the relative risks of the various examinations that they routinely perform. This is understandable given the numerous confusing methods used and quoted in radiation physics. However, there is increasing awareness among clinical colleagues and the public that we should actually know and adjust our practice accordingly.

The dangers of radiation have been known since the early days of its usage in clinical medicine. Every attempt should be made to reduce the exposure to harmful and excessive radiation. Most of the legislation is designed to ensure the safety of staff using ionising radiation. While clinicians are obligated to minimise doses administered to patients, strictly speaking there are no dose limits for patients. ${ }^{4}$ While large radiation doses can also result from fluoroscopic studies and interventional procedures, this article concentrates on computed tomography (CT) examinations as CT might contribute as much as $40 \%$ of the total collective dose to the population, while representing only $4 \%$ of the total number of medical examinations. ${ }^{5,6}$ In addition, newer CT indications and examinations, e.g. triplephase liver studies, have also increased the radiation doses when compared with standard $\mathrm{CT}^{6,7}$

None of the authors of this article is a radiation physicist, and this is not intended to be a specialised technical article on radiation protection. The aim of this article is to highlight for all our colleagues the significant radiation doses received by patients (especially children) undergoing CT scans and to discuss practical ways to reduce patient exposure.

Referring physicians should make sure a CT examination is indicated for a child and find out how it will be done. 'Ask: "What factors do you use on adults" and "what will you use on a child?" If they look the same, I would go elsewhere.'

Fred Mettler

Chair of Radiology

University of New Mexico

Albuquerque, USA

Chair of International Commission of Radiation Protection

The basic requirements are to adjust the mAs downward and increase the pitch. That's all there is to it. Get with it!'

Lee F Rogers

Editor in Chief American Journal of Roentgenology 


\section{Discussion}

\section{A brief overview of radiation physics}

The old units for absorbed dose and absorbed dose equivalent were the rad and rem respectively; the currently used International System (SI) of units are the Gray (Gy) and Sievert (Sv) respectively. One Gray is equal to $100 \mathrm{rad}$ and one Sievert is equal to 100 rem. The Gray is the unit of absorbed dose and is defined as the quantity of radiation that results in an energy deposition of one joule per kilogram within the irradiated material. The Sievert is the unit of absorbed or effective dose equivalent $\left(\mathrm{H}_{\mathrm{T}}\right)$, and is equal to the absorbed dose in Gray multiplied by a weighting factor. Fortunately for radiologists, the weighting factor for X-rays is one, so for practical purposes a Gray is exactly equal to a Sievert. A Gray or Sievert is a large unit and as most doses received from diagnostic X-ray examinations are in the milliSievert $(\mathrm{mSv})$ range $(1000$ $\mathrm{mSv}=1 \mathrm{~Sv}$ ), these smaller units are more frequently used. To add to the confusion, the Sievert is also the unit for effective dose (E) defined as the sum of the absorbed or effective dose equivalents in the various tissues and organs, multiplied by their tissueweighting factors $\left(w_{T}\right)$, i.e. $E=' \Sigma$ ' $w_{T}$ $\times \mathrm{H}_{\mathrm{T}}$. This takes into account the risk associated with a particular radiological examination depending on which organs are irradiated and the dose received by each of them. Though not exactly the same, the effective dose equivalent and effective dose are almost always of the same order of magnitude. ${ }^{4}$ Since the above doses are calculated using estimated weighting factors that have been modified over the years by the International Commission on Radiological Protection (ICRP), the values for specific examinations quoted in the literature may not correlate. However, it is acceptable to make broad comparisons using these values. ${ }^{8}$ Other frequently quoted comparable units used in radiation protection are air kerma, entrance surface or entrance skin dose with backscatter (ESD) and dose-area-product (DAP). The latter two are relatively easily measured in a radiology department, can be compared with published national guidelines and may well form part of a

Table I. Comparison of the typical effective dose equivalent $\left(\mathrm{H}_{\mathrm{T}}\right)$ for several plain film investigations in adults expressed in terms of the number of chest X-rays and length of exposure to background radiation which would give the same dose ${ }^{4}$

\begin{tabular}{lccc}
\hline Examination & $\begin{array}{l}\text { Average effective } \\
\text { dose equivalent } \\
(\mathrm{mSv})\end{array}$ & $\begin{array}{l}\text { Equivalent number } \\
\text { of chest X-rays }\end{array}$ & $\begin{array}{l}\text { Equivalent length of } \\
\text { background } \\
\text { exposure (BERT) }\end{array}$ \\
\hline Chest & 0.05 & 1 & 1 week \\
Skull & 0.15 & 3 & 3 weeks \\
Lumbar spine & 2.1 & 42 & 10 months \\
Barium enema & 7.7 & 154 & 3 years 1 month
\end{tabular}

BERT $=$ background equivalent radiation time.

future quality control programme. . $^{4,10}$ Other units of radiation dose in CT include CT dose index (CTDI), multiple scan average dose (MSAD) and dose-length product (DLP). ${ }^{5.6 .11} \mathrm{To}$ avoid confusion these units will not be used in this article.

\section{An overview of radiation protection}

The ICRP guidelines state that a radiation worker should not receive more than $20 \mathrm{mSv}$ per year over a 5 -year period, and not more than $50 \mathrm{mSv}$ in any one of those years. In comparison, to put this into perspective, every individual in the population receives approximately $2.5 \mathrm{mSv}$ from background radiation per year from the environment. ${ }^{4}$ Table I compares the typical effective dose equivalent $\left(\mathrm{H}_{\mathrm{T}}\right)$ for several plain film investigations and also expresses them in terms of the number of chest X-rays and length of exposure to background radiation that would give the same dose. ${ }^{4}$ This last method, which has been recommended by the United States National Council for Radiation Protection and Measurement (NRCP), is called background equivalent radiation time (BERT) and is useful when explaining radiation dose to a patient. ${ }^{12}$

\section{Radiation doses received in adult radiology}

There are a lack of published data on comparable doses for CT examinations. A chest $\mathrm{X}$-ray is the commonest radiological examination (41\%) and will be used as the reference value for the following comparisons. ${ }^{6}$ The absorbed dose equivalents $\left(\mathrm{H}_{\mathrm{T}}\right)$ for adult radiographs versus $\mathrm{CT}$ examinations are shown in Table II. It can easily be appreciated that the doses 
Table II. Comparison of the typical effective dose equivalent $\left(\mathrm{HT}_{\mathrm{T}}\right)$ for several plain film and CT examinations in adults $(\mathrm{mSv})^{4,6}$

\begin{tabular}{llll}
\hline Examination & Plain film & CT $^{4}$ & CT $^{\mathbf{6}}$ \\
\hline Chest & 0.05 & 9.1 & 7.8 \\
Head & 0.2 & 3.5 & 1.8 \\
Abdomen & 1.4 & 8.8 & 7.6 \\
Pelvis & 1.2 & 9.4 & 7.1 \\
\hline
\end{tabular}

Table III. Comparison of effective doses (E) in $\mathrm{mSv}$ for chest radiographs in children

\begin{tabular}{llllll}
\hline Reference & Examination & Newborn & $\begin{array}{l}\mathbf{1 - 4} \\
\text { years of } \\
\text { age }\end{array}$ & $\begin{array}{l}\mathbf{5 - 9} \\
\text { years of } \\
\text { age }\end{array}$ & $\begin{array}{l}\mathbf{1 0 - 1 4} \\
\text { years of } \\
\text { age }\end{array}$ \\
\hline Staniszewska $^{13}$ & AP & 0.21 & 0.18 & 0.18 & 0.08 \\
Own data & PA/AP & 0.049 & 0.059 & 0.055 & - \\
Own data & LAT & 0.077 & 0.083 & 0.072 & -
\end{tabular}

$\mathrm{AP}=$ antero-posterior chest $\mathrm{X}$-ray; $\mathrm{PA}=$ postero-anterior chest $\mathrm{X}$-ray; $\mathrm{LAT}=$ lateral chest $\mathrm{X}$-ray.

from CT studies are significantly higher than those arising from plain film examinations. A CT of the chest is equivalent to approximately 180 chest X-rays. ${ }^{4}$

\section{Radiation doses received in paediatric radiology}

Table III shows the estimated effective doses (E) for chest X-rays in children from a Polish study ${ }^{13}$ and from calculations performed at our institution, the Red Cross War Memorial Children's Hospital, using reference sources. ${ }^{14,15}$ The typical paediatric postero-anterior $(\mathrm{PA})$ chest $\mathrm{X}$ ray has an effective dose of $0.02-0.04$ $\mathrm{mSv} .^{16}$ Our figures are slightly higher, probably as a result of our institution still using a Quanta detailed screen with an Agfa CPM half-speed blue film. An Agfa CPG+ green-screen system is currently being installed and is expected to lower the doses signifi- cantly. But what about doses received from CT? The United Kingdom National Radiological Protection Board (NRPB) has stated that the effective dose will underestimate the detrimental effect of paediatric exposure by about a factor of two. ${ }^{8}$ In addition, a study using abdominal CT showed that the effective dose was $50 \%$ higher in children compared with adults. ${ }^{17}$ As of early 2001 there are no published reference figures available for children on the effective dose received from $\mathrm{CT}$ examinations. ${ }^{6}$

\section{Radiation risks}

The risks of low doses of radiation are tumour induction and genetic damage. However, these risks are difficult to calculate. The ICRP estimate of risk of death from fatal cancer of $5 \%$ per Sv was extrapolated from the higher doses received by Japanese atomic bomb survivors. The lowest dose at which there was evidence of deleterious effects in the atomic bomb survivors was $100 \mathrm{mSv}$, i.e. about tenfold the dose from an adult chest CT scan. ${ }^{18}$

The advent of fast helical CT has been attractive in paediatric examinations where sedation and co-operation are often difficult. This is supported by American data which have shown increases in the number of paediatric CT examinations of $63 \%$ between 1991and 1994 and 92\% between 1996 and 1999. It has been estimated that the lifetime cancer mortality risk attributable to the radiation exposure from a single abdominal CT examination in a 1-year-old child is approximately 1:550, and approximately $1: 1500$ for a head CT examination. To put this into perspective, of the estimated 600000 children under 15 years old who undergo CT each year in the USA, approximately 140000 will ultimately die of cancer. The estimated projected 500 CT-related deaths, however, represent about a $0.35 \%$ increase over this background mortality. ${ }^{19}$

\section{How to reduce radiation dose in paediatric CT examinations}

In CT, patient dose is proportional to the X-ray beam thickness, tube current and exposure time selected for each slice or helical scan, and the number of such exposures per examination. Significant variations have been observed between individual scanners with regard to the typical dose for a given type of procedure: factors of $10-40$ over all makes of scanners and factors of $5-20$ when each scanner model was considered separately. ${ }^{5,20} \mathrm{~A}$ low-dose chest CT can be performed at $20 \mathrm{~mA}$ rather than 
$140-280 \mathrm{~mA}$ ? $^{7}$ A recent study has shown that low-dose spiral CT of the paediatric chest can reduce the radiation dose to $5-20 \%$ of standard-dose CT without affecting the image quality. ${ }^{21}$ Similar results with reductions in dose of up to $80 \%$ have also been reported for high resolution CT scanning (HRCT). ${ }^{22}$

Unlike conventional radiography, $\mathrm{CT}$ allows considerable latitude in the exposure required to produce a diagnostically acceptable image. Over- and underexposure in conventional filmscreen radiographs are immediately noticed. With CT the pre-programmed adult settings will produce an acceptable image for a child as well as for an adult - the computer will make the necessary adjustments in the post-processing stage. ${ }^{1.23}$ These may not be the most optimal milliampere seconds (mAs) settings. ${ }^{24,25}$ A review of techniques of paediatric helical CT examinations performed elsewhere and submitted for second interpretation showed that average tube current settings used exceeded those typically suggested for an adult and were not adjusted on the basis of the examination type or the age or size of the child. ${ }^{26}$

The most important factor that can be changed is tube current. A $50 \%$ reduction in tube current results in a decrease in radiation dose of $50 \%$. The potential for increased noise caused by decreasing the tube current in younger patients is counterbalanced by the smaller size of these patients. ${ }^{6,23}$ Table IV shows suggested tube currents by weight of paediatric patient for a single-detector helical CT. In the uncommon situation where very small lesions may be present, such as in an immunocompromised child with suspected fungal liver disease, the values in Table IV may be increased by $50 \mathrm{~mA}$ to decrease noise. ${ }^{23}$

The second most important factor that can be adjusted is pitch. For a one-second gantry rotation (the standard among most CT scanners), pitch can be calculated by dividing the table speed by the collimation width. For example, a table speed of $10 \mathrm{~mm} / \mathrm{sec}$ ond with a collimation of $10 \mathrm{~mm}$ gives a pitch of one. If the collimation was changed to $5 \mathrm{~mm}$, the pitch would change to two. When the pitch is doubled, the radiation dose is reduced by half. ${ }^{6,23} \mathrm{~A}$ recommended standard pitch for paediatric patients is 1.5 , which can be increased to 1.7 or 2 for follow-up examinations. A

Table IV. Suggested tube current $(\mathrm{mA})$ by weight (weights in original table in pounds) for paediatric patients for a single-detector helical $\mathrm{CT}^{23}$

\begin{tabular}{lcc}
\hline Weight $(\mathbf{k g})$ & Chest $(\mathbf{m A})$ & Abdomen or pelvis $(\mathbf{m A})$ \\
\hline $4.5-8.9$ & 40 & 60 \\
$9.0-17.9$ & 50 & 70 \\
$18.0-26.9$ & 60 & 80 \\
$27.0-35.9$ & 70 & 100 \\
$36.0-45.0$ & 80 & 120 \\
$45.1-70.0$ & $100-120$ & $\geq 10-150$ \\
$>70$ & $\geq 140$ & \\
& & \\
\hline
\end{tabular}

change in collimation (with constant $\mathrm{mAs}$ ) does not significantly affect radiation dose. A thinner collimation is preferred in children because of their smaller size. ${ }^{23}$

Most children do not need an uncontrasted CT scan when intravenous contrast is going to be given. In addition, inappropriate referrals for CT examinations can also be eliminated and converted to alternative examinations such as ultrasound and MRI. ${ }^{6.23} \mathrm{CT}$ chest examinations in girls and young females need to be justified in view of the higher risks of radiogenic breast cancer in this age group. CT scans through the base of the skull in children can give high doses to the thyroid and it is preferable to shield this organ. However, when the gonads are not included in the examination field the small dose received is due to internal scatter and hence external shielding is not effective. There are other methods that the manufacturer can use to reduce the radiation dose received during $\mathrm{CT}$ examinations, but not many of these have been introduced as yet. ${ }^{\circ}$

\section{Conclusion}

The radiation dose received by patients from CT scans is probably significantly higher than most radiologists realise. Instead of a knee-jerk reaction, of trying to reduce the number of indications for CT scanning, an effort should be made to publicise the fact that a reduction in dosage can be obtained by altering the exposure settings to optimum levels. Ultimately, while CT scanners will always have a significant role to play, advances in ultrasound machines, increased availability of MRI scanners and imaging with ${ }^{18} \mathrm{~F}$-fluorodeoxyglucose positron emission tomography (FDG PET) 


\section{REVIEW ARTICLE}

should result in a reduction in the radiation dose received by everyone - especially children. ${ }^{25}$ We hope that this article provokes discussion, a change in day-to-day practice and further investigation into methods to accomplish this goal.

\section{Acknowledgements}

We thank Dr Egbert Hering, Head of the Department of Radiation Physics and Professor Steve Beningfield, Head of the Department of Radiology at the University of Cape Town for their review of this article, and Gerrie Maree of the Directorate: Radiation Control at the Department of Health for his assistance with radiation dose measurements.

\section{References}

1. Rogers LF. Taking care of children: Check out the parameters used for helical CT. AJR 2001; 176: 287.

2. Larkin M. Radiation overdose common in CT scans of children. Lancet 2001; 357: 285.

3. Kids, CAT scans, cancer. TIME, 5 February 2001: 45.

4. Robinson A. Radiation protection and patient doses in diagnostic radiology. In: Grainger RG, Allison DJ, eds. Diagnostic Radiology: A Textbook of Medical Imaging. 3rd ed. New York: Churchill Livingstone, 1997: 169-189.
5. National Radiological Protection Board. Guidelines on patient dose to promote the optimisation of protection for diagnostic medica exposures. Documents of the National Radiological Protection Board 1999; 10(1): 2633.

6. International Commission on Radiation Protection. Managing patient dose in computed tomography. Draft version, 13 October 2000. www.icrp.org/pr01.htm

7. Berdon WE. Spiral CT: Use, misuse and safety issues (Editorial comment). Pediatr Radiol 1999; 29: 721-722.

8. National Radiological Protection Board. Occupational, public and medical exposure. Documents of the National Radiological Protection Board 1993; 4(2): 45-61.

9. National Radiological Protection Board. Patient dose reduction in diagnostic radiology. Documents of the National Radiological Protection Board 1990; 1(3): 22

10. International Commission on Radiation Protection. Diagnostic reference levels in medical imaging. Draft version, 5 February 2001. www.icrp.org/draft_diagnostic.htm

11. Hidajat N, Mäurer J, Schröder R-J, et al. Relationships between physical dose quantities and patient dose in CT. Br J Radiol 1999; 72: 556-561.

12. National Council on Radiation Protection and Measurements. Research needs for radiation protection. NCRP Report No. 117. Bethesda: NCRP Publications, 1993.

13. Staniszewska MA.X-ray diagnostics as the main source of ionising radiation for the general Polish population. J Radiol Prot 1993; 13: 275278.

14. National Council on Radiation Protection and Measurements. Medical x-ray electron beam and gamma-ray protection for energies up to 50 MeV. NCRP Report No. 102. Bethesda: NCRP Publications, 1989.

15. Rosenstein M, Beck TJ, Warner GG. Handbook of Selected Organ Doses for Projections Common in Pediatric Radiology. US Department of Health, Education and Welfare (FDA) BRH. Rockville: HEW Publications (FDA) 79-8079, 1979.

16. Koh DM, Hansell DM. Computed tomography of diffuse interstitial lung disease in children. Clin Radiol 2000; 55: 659-667.

17. Ware DE, Huda W, Mergo PJ, Litwiller AL Radiation effective doses to patients undergoing abdominal CT examinations. Radiology 1999; 210: 645-650.

18. Hall E. Commentary on Roebuck DJ: "Risk and benefit in paediatric radiology". Pediatr Radiol 1999; 29: 721-722.

19. Brenner DJ, Elliston CD, Hall EJ, Berdon WE Estimated risks of radiation-induced fatal cancer from pediatric CT. AJR 2001; 176: 289-296.

20. National Radiological Protection Board Protection of the patient in $\mathrm{x}$-ray computed tomography and further statements on radon affected areas. Documents of the National Radiological Protection Board 1992; 3(4): 3-11.

21. Rogalla P, Stöver B, Scheer I, Juran R, Gaedicke G, Hamm B. Low-dose spiral CT: applicability to paediatric chest imaging. Pediatr Radiol 1999; 29: 565-569.

22. Lucaya J, Piqueras J, García-Pena P, Enríquez G, García-Macías M, Sotil J. Low-dose high-resolution CT of the chest in children and young adults: Dose, cooperation, artefact incidence, and image quality. AJR 2000; 175: 985-992.

23. Donnelly LF, Emery KH, Brody AS, Laor T, et al. Minimising radiation dose for pediatric body applications of single-detector helical CT: Strategies at a large children's hospital. AJR 2001; 176: 303-306

24. Roebuck DJ. Risk and benefit in paediatric radiology. Pediatr Radiol 1999; 29: 637-640.

25 Frush DP, Donnelly LF, Chotas HG. Contemporary pediatric thoracic imaging. AJR 2000; 175: 841-851.

26. Paterson A, Frush DP, Donnelly LF. Helical CT of the body: Are settings adjusted for pediatric patients? AJR 2001; 176: 297-301. 